\title{
Pace Regresyon Algoritması İle Kaynama Isı Transferinde Isı Akısının Modellenmesi
}

\author{
Erdem Alıç ${ }^{1 *}$, Mehmet Daş ${ }^{2}$ \\ 1*Kahramanmraş Sütçü İmam Üniversitesi, Andırın Meslek YüksekOkulu, Kahramanmaraş, Türkiye (ORCID: 0000-0002-2852-0353) \\ 2 Tokat Gaziosmanpaşa Üniversitesi Mühendislik Mimarlık Fakültesi, Makine Mühendisliği Bölümü, Tokat, Türkiye (0000-0002-4143-9226) \\ E-mail: ealic@ksu.edu.tr, mehmet.das@gop.edu.tr
}

(International Symposium on Multidisciplinary Studies and Innovative Technologies (ISMSIT) 2020 - 22-24 Ekim 2020)

(DOI: $10.31590 /$ ejosat.819017)

ATIF/REFERENCE: Alıç, E. \& Daş, M. (2020). Pace Regresyon Algoritması İle Kaynama Isı Transferinde Isı Akısının Modellenmesi. Avrupa Bilim ve Teknoloji Dergisi, (Özel Sayı), 43-49.

$\ddot{\mathbf{O z}}$

Küçük sıcaklık farkları ile yüksek miktarda enerji dönüşümüne imkân sağlayan kaynama ısı transferi, buhar kazanları, 1sı değiştiricileri, enerji sistemleri ve nükleer santral reaktörleri gibi birçok alanda araştırılmaktadır. Bu çalışmada daha önce deneysel olarak çalı̧ılmış silindirik metal yüzey üzerinde izole buhar kabarcığı bölgesinde gerçekleşen kaynama ısı transferi incelenmiştir. Yüzey malzemesi olarak pürüzsüz çelik seçilmiştir. Deneysel verilerle hesaplanmış metal malzemenin yüzeyinde gerçekleşen havuz kaynama isı transferi sonucu ortaya çıkan $1 S 1$ akısı değerleri, bir makine öğrenmesi algoritması olan Pace regresyon algoritması ile ilk kez modellenmiştir. Pace regresyonda 2 farklı metot sonucu üretilen veriler ile deneyler sonucunda elde edilen veriler karşılaştırılmıştır. Çelik malzeme için 0.132 (RAE) hata oranı ile 1sı akısı başarılı bir şekilde PG algoritması OLS metodu tarafindan modellenmiştir.

Anahtar Kelimeler: Havuz kaynama, Isı transferi, Isı akısı, Pace regresyon

\section{Experimental and Numerical Analysis of a Trapezoidal Absorber Plate Air Solar Collector}

\begin{abstract}
Boiling heat transfer, which allows a large amount of energy conversion with small temperature differences, has been investigated in many areas such as steam boilers, heat exchangers, energy systems and nuclear power plant reactors. In this study, the boiling heat transfer occurring in the isolated vapor bubble region on the cylindrical metal surface, which was experimentally studied before, was investigated. Smooth steel has been chosen as the surface material. The heat flux values resulting from pool boiling heat transfer on the surface of the metal material calculated with experimental data were modeled for the first time with the Pace regression algorithm, which is a machine learning algorithm. The data obtained as a result of 2 different methods in pace regression were compared with the data obtained from the experiments. With an error rate of 4.06 (RMSE) for steel, the heat flux was successfully modeled by the PG algorithm OLS method.
\end{abstract}

Keywords: Pool boiling, Heat transfer, Heat flux, Pace regresyon

\footnotetext{
* Sorumlu Yazar: Kahramanmraş Sütçü İmam Üniversitesi, Andırın Meslek Yüksekokulu, Kahramanmraş, Türkiye, ORCID: 0000-0002-2852-0353, ealic@ksu.edu.tr
} 


\section{Giriş}

Makine öğrenmesi algoritmaları özellikle YSA'lar (yapay sinir ağı) bilim ve mühendisliğin birçok alanında yaygın olarak kullanılmaktadır[1]-[5]. Yapay zeka, makinelerin insanlar gibi davranmasını sağlamanın bir yolu olarak karşımıza çıkmaktadır. Yani belirli bir sorunu çözerken zeki bir insanın düşündüğü gibi akıllıca düşünen yazılımlar ve sistemler geliştirilmesidir. Bu süreçler içerisinde öğrenme, akıl yürütme, problem çözme, algılama, planlama, vb konular yer almaktadır. Yapay zekanın belirli uygulamaları arasında uzman sistemler kurma, oyun oynama, görüntü işleme, konuşma, tanıma ve makine öğrenmesi bulunmaktadır.

YSA modellerinin temel avantajları şunlardır: (1) modellenen sistem hakkında özel bir bilgiye gerek yoktur, girdi-çıtı modellerinin uygun bir şekilde tasarlanmasıyla bilinmeyen etkiler dahil edilebilir; (2) sinir ağı mimarisinin göreceli basitliği; (3) YSA'ların stokastik sinyalleri yeniden üretme kabiliyetinin yüksek olmasıdır.

Ertunç çalışmasında çeşitli çalışma koşulları altında dielektrik sıvılar için havuz kaynayan kritik ısı akısının (CHF) yapay sinir ağı (YSA) tabanlı tahminini ele almaktadır. YSA'nın deneysel ve tahmin edilen CHF'ler arasında 0,996 korelasyon katsayısı, \%8,81 ortalama bağı hata ve $0,97 \mathrm{Wcm}^{-2}$ kök ortalama kare hatası ile tatmin edici bir korelasyon sağladığı bulunmuştur. Çalışması ile CHF kaynayan havuzun alternatif olarak çok yüksek bir doğruluk derecesi ile makine öğrenme algoritmaları kullanılarak tahmin edilebileceğini göstermektedir[6].

Fazel vd. Genetik Algoritma (GA) algoritması izole bölge kaynama 1sı transferinde ile 1sı akısı hesabını optimize etmeye çalışmıştır. Deneysel sonuçlarını en iyi ifade eden katsayıları belirlemiştir. Bu modelde GA \%26 ortalama mutlak hata ile sonuçlara yaklaşmışır[7].

Alıç vd. çalışmalarında Yapay Arı Kolonisi (YAK) algoritması ile kaynama 1sı transferine etki eden 6 1sı transfer mekanizmasına bağlı bir ısı akısı hesabı modelini optimize etmeye çalışmışlardır. İnceledikleri 1sı transfer mekanizmaları literatürde yer alan ifadelerdir. $\mathrm{Bu}$ ifadelerin toplamı ile elde edilen $1 \mathrm{~s} ı$ akısı için toplama etki eden kat sayıları belirlemeye çalışmışlardır. YAK algoritması \%25 ortalama mutlak hata ile sonuçlara yaklaşmıştır[8].

Alıç vd. çalışmalarında kaynama ısı transferini farklı hesapsal zeka yöntemleri ile modellemeye çalışmışlardır. Isı akısı tahmini için saf su ve diğer akışkanlarda da kullanılabilecek 19 parametre ile model oluşturmuşlardır. En iyi model destek vektör makinesi ile elde edilen ortalama mutlak hatas $\% 17$ olan modeldir[9].

Barroso-Maldonado vd. çalışmalarında mikro kanallarda nitrojen, metan, etan ve propan dahil olmak üzere azeotropik olmayan karışımların kaynaması sırasında sürtünme basınç düşüşünü tahmin etmek için yeni bir metodoloji önermektedir. Önerdikleri YSA metodolojisinin doğal gazın sıvılaştııılmasına benzer kriyojenik uygulamalarda kullanılan isı eşanjörlerinin termal analizine, derecelendirilmesine ve / veya boyutlandırılmasına yardımcı olabileceğini ifade etmişlerdir[10].

Parveen vd. mikro/mini kanal içerisinde akış kaynamasında yapay zekâ modellemeleri çalışmışlardır. Akışkan olarak R134-a kullanmışlardır. Yapay zekâ modelleri olarak gen ifade proğramlama (Gï), YSA ve Destek vektör makinesi regresyonu (DVR) kullanmışlardır. Simule edilen sonuçlarda DVR diğerlerinden daha düşük ortalama mutlak bağıl hata (AARE) ve R2 (\%3.62 ve 0.9749) ile modelleme gerçekleştirmiş̧ir[11].

Bu çalışmada izole bölgede gerçekleşen kaynama 1sı transferinde farklı yüzey malzemesine sahip silindirik ısıtıcıda gerçekleşen 1Sı transferinin PG ile modellenmesi amaçlanmıştır. PG algoritması bu amaçla literatürde ilk defa denenmiştir. Yapılan modellemede elde edilen sonuçlar deneysel veriler ile karşılaştırılmıştır.

\section{Materyal ve Metot}

Bu çalışmada havuz kaynama 1sı transferinde ısı akısı tahmini için bir makine öğrenmesi algoritması olan PACE regresyon analizi kullanılarak 1sı akısı tahmini gerçekleştirilmiştir. Bunun için bir havuz kaynama deney seti kurulmuştur. Bu deney seti ile ilgili detaylı bilgi aşağıda verilmiştir.

\subsection{Deneysel Kurulum}

Deneysel kurulum Şekil 1'de ayrıntılı yer almaktadır. Kaynama kazanı 25 lt kapasiteli ve temperlenmiş camdan yapılmıştır. Geometrik ölçüleri 250*220*300 mm dir. Isıtıcı açısını değiştirmek için açı ayarlı divüzör tasarlanmıştır. Kullanılan 1sıtıcı $20 \mathrm{~mm}$ çapında ve $100 \mathrm{~mm}$ boyunda paslanmaz çeliktir. Isıtıcının yüzey pürüzlülüğü $\mathrm{Ra}=0.119 \mu \mathrm{m}$ dir. Yüzey pürüzlülüğü 20 farklı noktadan alınarak ortalaması hesaplanmıştır. Hommel W5 yüzey pürüzlülük cihazı ile ölçülmüştür. Deneylerde kullanılan 1sıtıcı açıları Şekil 2 de gösterilmiştir. Deney sıvısı olarak saf su kullanılmıştır. 


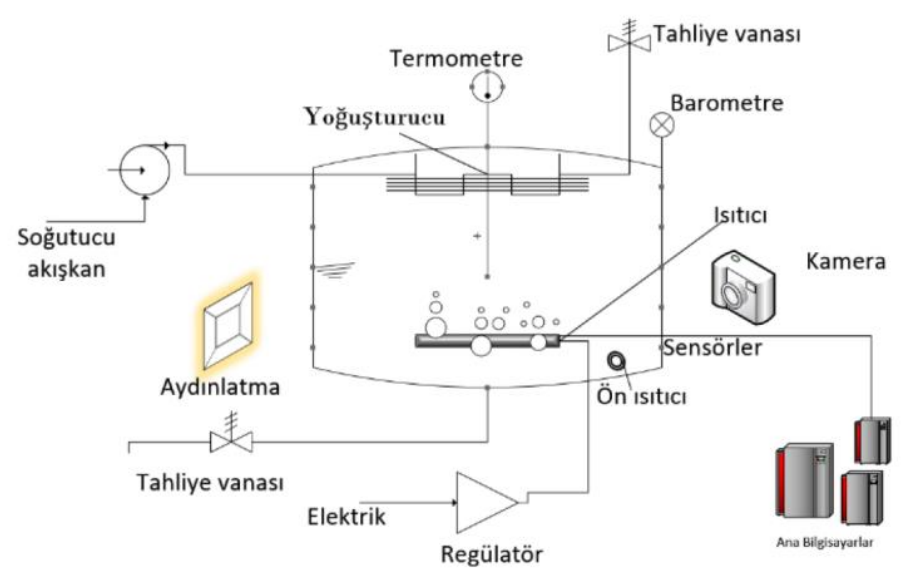

Şekil 1. Deneysel kurulum

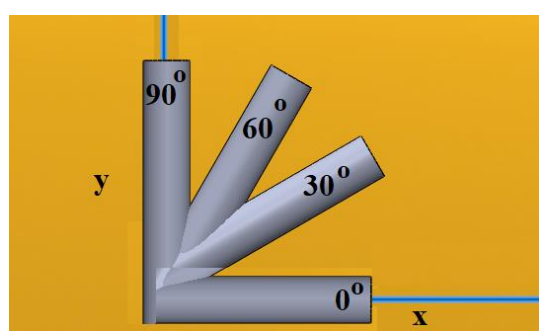

Şekil 2. Isıtıcı açıları

Yüzey sıcaklığı ölçümü için 1sıtıcı içerisinde 4 adet K tipi termokupl yerleştirilmiştir. Isı transfer katsayısı hesabı için dört termokupl elde edilen sonuçların ortalaması alınmıştır. Deney setinde voltaj düzenlemesi için varyak kullanılmıştır. Deneyler atmosferik basınçta gerçekleştirilmiş̧ir.

\subsection{Hesaplamalar}

Kaynama 1sı transferi hesabı için 18 parametrenin bilinmesi gerekmektedir. Bunlar (1) (q / A ), (2) $T_{y}$, (3) $T_{d}$, (4) d, (5) NA, (6) f,

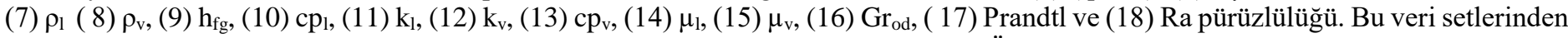
bazıları, (1) $\mathrm{T}_{\mathrm{y}}$, (2) $\mathrm{T}_{\mathrm{d}}$, (3) d, (4) NA, (5) f , (6) Ra, gibi deneylerden elde edildi. Öte yandan, geri kalanı EES (mühendislik hesap programı) paket programından elde edilmiştir. Bu veriler için ortalama sıcaklık farkı metodu kullanılmıştır. Deneysel hesaplamalar için aşağıda yer alan 4 eşitlik kullanılmıştır. Burada Eş.l'de yer alan $\mathrm{V}$ voltmetrede ölçülen voltaj değerini göstermektedir, I ampermetrede ölçülen akım değerini göstermektedir. Eş.2'de yer alan A 1sıtıcı yüzey alanını ifade etmektedir. Eş.2. de yer alan q" 1Sı akısını ifade etmektedir. Eş. 3'de yer alan hy yerel 1sı transfer katsayısını ifade etmektedir, Ty 1sıııcı yüzey sıcaklığını, Td sıvı doyma sıcaklığını ifada etmektedir. Eş. 4'de yer alan Tk termokupldan ölçülen sıcaklığı ifade etmektedir.

$$
\begin{aligned}
& Q=V . I \\
& q^{\prime \prime}=V . I / A \\
& h_{\mathrm{y}}=\frac{q^{\prime \prime}}{T_{y}-T_{d}} \\
& T_{y}=T_{k}-\frac{s}{k} q^{\prime \prime}
\end{aligned}
$$

\subsection{Pace Regresyon}

Regresyon analizi, iki ya da daha çok değişken arasındaki ilişkiyi ölçmek için kullanılan analiz metodudur. Eğer tek bir değişken kullanılarak analiz yapılıyorsa buna tek değişkenli regresyon, birden çok değişken kullanılıyorsa çok değişkenli regresyon analizi olarak isimlendirilir [12].

PACE(Projection Adjustment by Contribution Estimation) regresyon algoritması benzer modellerin dikkate alınmasına dayanan doğrusal modellere uymaya yönelik yeni bir yaklaşımdır [13]. Regresyon analizinin temel fikri, doğrusal bir modeli bir veri kümesine uydurmaktır. Klasik sıradan en küçük karenin tahmin özelliği basittir ve sağlam bir teorik gerekçeye sahiptir. Bununla birlikte, üretilen 
modeller genellikle tatmin edici değildir. PACE regresyonu, her değişkenin etkisini değerlendirerek genel regresyonlara katkılarını tahmin etmek ve istatistiksel temeli geliştirmek için bir kümeleme analizi kullanarak klasik sıradan en küçük karelerin regresyonunu iyileştirir [14]. Wang ve Witten page regresyonunu geliştirmiş ve yüksek boyutlu veriler için diğer regresyon modellerine kıyasla en iyi performansı gösterdiğini göstermiştir [15].

Değişkenlerin etkilerinin verilerden dağılımını tahmin eden ve bunu modellemeyi geliştirmek için kullanan ortak bir temel fikri paylaşan, PACE1'den PACE6'ya kadar adlandırılan altı farklı regresyon prosedürü geliştirildi. İlk dört prosedür, OLS'nin kendisi dahil OLS (sıradan en küçük kare) alt küme seçimini kullanır. PACE 5 ise deneysel bayes (Emprical Bayes) metoduna dayanmaktadır [14].

Diğer doğrusal regresyon formlarında olduğu gibi, herhangi bir parametreyi modellemek için kullanılan PACE regresyon OLS ve Emprical Bayes metodu Eş. 5' deki formatta özelliklerin lineer bir kombinasyonudur [14].

OLS ile Modellenen Parametre $=\alpha 1 * \mathrm{Ai}+\alpha 2 * \mathrm{Bi}+\alpha 3 * \mathrm{Ci}+\alpha 4 * \mathrm{Di}+\alpha 5 * \mathrm{Ei}+\ldots$

Eşitlik 1 de A,B,C,D,E gibi ifadeler modellenen parametre için oluşturulan ağ yapısındaki giriş parametreleridir. $\alpha i$ değerleri ise Pace regresyon metodları tarafından elde edilen parametreleri etkileyen ağırlık katsayılarıdır. Ortaya çıkan modelin, özelliklerin doğrusal bir kombinasyonu olduğuna dikkat etmek önemlidir. Bu şekilde basitleştirilmiş bir tahmin modeli elde edilebilir ve model hesaplama süresi azalabilir. Pace regresyon metotları kullanılarak modellen Q/A için oluşturulan ağ yapısı giriş ve çıkış parametreleri Tablo 1'de verilmiştir.

Tablo 1. Pace Regresyon metotları ile oluşturulan modelin ă̆ yapısı için kullanılan giriş ve çıkış parametreleri

\begin{tabular}{|c|c|}
\hline Giriş Parametreleri & Birim \\
\hline Isıtıcı açısı & Rad. \\
\hline$\Delta T($ Doyma slcaklı̆̆l - Yüzey Sıcaklı̆̆l) & ${ }^{\circ} \mathrm{C}$ \\
\hline$d$ (Buhar kabarcık çapı) & $m m$ \\
\hline$N$ (Buhar kabarcık sayısı) & Adet \\
\hline Td (Doyma Slcaklı̆̆ $)$ & ${ }^{\circ} \mathrm{C}$ \\
\hline rho_slvı (Sivının yoğunluğu) & $\left(\mathrm{kg} / \mathrm{m}^{3}\right)$ \\
\hline rho_buhar( Buharın yoğunluğu) & $\left(\mathrm{kg} / \mathrm{m}^{3}\right)$ \\
\hline$h$ fg (Buharlaşma entalpisi) & $(\mathrm{J} / \mathrm{kg})$ \\
\hline$c p \_v($ Buhar özğgül lsssı) & $(\mathrm{J} / \mathrm{kg} * \mathrm{~K})$ \\
\hline$m u \_L$ (Sivının Viskozitesi) & $(\mathrm{kg} / \mathrm{m} * \mathrm{~s})$ \\
\hline k_liquit ( sıvının ısıl iletkenlik katsayısı) & $(W / m * K)$ \\
\hline$k \_v$ (buhar $ı$ sil iletkenlik katsayısı) & $(W / m * K)$ \\
\hline Grod (Grod sayısı) & - \\
\hline Pr_L ( Slvının prandtl sayısı) & - \\
\hline Ja (Jakob sayısı) & - \\
\hline SIGMA (Yüzey gerilimi) & $\left(\mathrm{Nm}^{-1}\right)$ \\
\hline Çıkış Parametresi & Birim \\
\hline$q / A$ & $\mathrm{Watt} / \mathrm{m}^{2}$ \\
\hline
\end{tabular}

PR yönteminde OLS ve Deneysel bayes metodu ile modellenen Q/A değerleri için kullanılan hata analiz yöntemi Tablo 2 de verilmiştir [16]. Tablo 2 de MAE (ortalama mutlak hata), RAE (göreceli mutlak hata), RMSE(kök ortalama mutlak hata) analizleri verilmiştir.

Tablo 2. Hata analiz yöntemi förmül ve parametreleri

\begin{tabular}{|c|c|c|}
\hline Hata Analizi & Formül & Parametreler \\
\hline \multirow[t]{3}{*}{ MAE } & & \multirow{3}{*}{$\begin{array}{l}\text { P: Tahmin Değeri } \\
\text { A: Gerçek Değer } \\
\text { n: Toplam Hata } \\
\text { Değeri }\end{array}$} \\
\hline & $\left|P_{1}-A_{1}\right|+\ldots \ldots+\left|P_{n}-A_{n}\right|$ & \\
\hline & $n$ & \\
\hline \multirow[t]{2}{*}{ RAE } & $\left|P_{1}-A_{1}\right|+\ldots \ldots+\left|P_{n}-A_{n}\right|$ & \multirow{2}{*}{$\begin{array}{l}\text { P: Tahmin Değeri } \\
\text { A: Gerçek Değer } \\
\text { A': Gerçek Değer } \\
\text { Ortalaması }\end{array}$} \\
\hline & $\left|A_{1}-A^{\prime}\right|+\ldots . .+\left|A_{n}-A^{\prime}\right|$ & \\
\hline \multirow[t]{2}{*}{ RMSE } & $\sqrt{\left(P_{1}-A_{1}\right)^{2}+\ldots \ldots+\left(P_{n}-A_{n}\right)^{2}}$ & \multirow{2}{*}{$\begin{array}{l}\text { P: Tahminsel veri } \\
\text { A: Gerçek veri } \\
\text { A': Toplam tahmin }_{\text {hata değeri }}\end{array}$} \\
\hline & & \\
\hline
\end{tabular}


Bu çalışmada, verileri Pace regresyon metotları kullanarak daha az hata oran ile modellemek için ten-fold cross-validation (10 kat çapraz doğrulama) tekniği uygulanmıştır. Cross-validation, bir makine öğrenimi modelindeki bir testin hatasını daha iyi tahmin etmek için model seçiminde kullanılan bir tekniktir. Çapraz doğrulamada eğitim verileri alt gruplara bölünür. Eğitim için bir alt küme kullanılır ve kalan kümeler doğrulama için kullanılır. Bu işlem, bir kesişme yolundaki tüm alt kümeler için tekrarlanır [9].

\section{Bulgular ve Tartışma}

\subsection{Deneysel Bulgular ve Tartışma}

Bu çalışmada havuz kaynamada çelik yüzeyli ısıtıcı için farklı açılarda sabit ısı akısında yüzey sıcaklığı değişi araştırılmıştır. Şekil

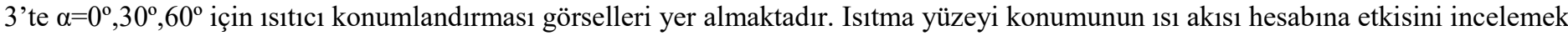
için böyle bir yöntem tasarlanmıştır. Literatürde yer alan mevcut korelasyonlar ile 1sı akısı hesabında ortalama mutlak hata \%50 ile \% 100’den fazla hata ile ısı akısı hesabı yapılmaktadır[17]. Bu çalışmada elde edilen yüzey sıcaklığı, 1Sı akısı ve 1sıtıcı konum açısınındı 1sı akısı hesabında önemli olabileceği gözlemlenmiştir.

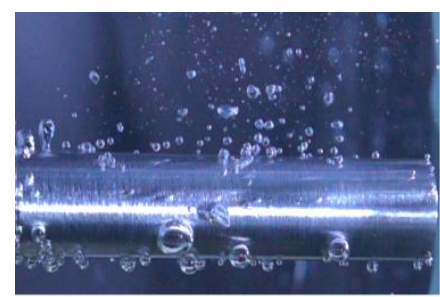

A)

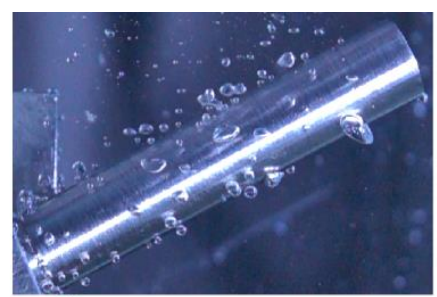

B)

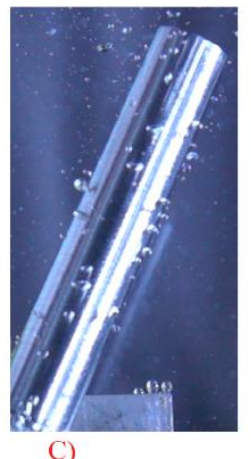

Şekil $3.29 \mathrm{~kW} / \mathrm{m}^{2}$ ısı akısında farklı açılarda ısıtıcı görünümü $\left(\right.$ A) $\left.\alpha=0^{\circ}, B\right) \alpha=30^{\circ}$, C) $\alpha=60^{\circ}$ )

\subsection{Pace Regresyon Modeli}

Çelik malzeme için kaynama 1Sı transferi incelenmiş ve izole edilen bölgedeki 1Sı transferi değerleri PR algoritması ile modellenmiştir. Yapılan modelleme sonucu Pace regresyon OLS metodu ve Deneysel Bayes metodu tarafindan elde edilen q/A denklemleri Tablo 3 de verilmiştir.

Tablo 3. Pace regresyonda ısı akısını modellemek için kullanılan metotlar sonucu elde edilen denklemler

\begin{tabular}{|c|c|c|}
\hline Metot & Denklem & No \\
\hline OLS & $\begin{array}{l}\mathrm{Q} / \mathrm{A}=-37192.134+\alpha_{1} . \text { Isitıcı Açısı }(\mathrm{Rad})+\alpha_{2} . \Delta \mathrm{T}+\alpha_{3} . \mathrm{d}+\alpha_{4} . \mathrm{N}+\alpha_{5} . \mathrm{Td}+ \\
\alpha_{6} . \mathrm{rho} \_\mathrm{S} 1 \mathrm{v} 1+\alpha_{7} . \mathrm{h} \_\mathrm{fg}+\alpha_{8} . \mathrm{mu} \_\mathrm{L}+\alpha_{9} . \mathrm{k} \_\mathrm{v}+\alpha_{10} . \mathrm{Gr} \_\mathrm{OD}+\alpha_{11} . \mathrm{Ja}+\alpha_{12} . \text { Sigma }\end{array}$ & (3) \\
\hline $\begin{array}{l}\text { Emprical } \\
\text { Bayes }\end{array}$ &  & (4) \\
\hline
\end{tabular}

Tablo 3 de Pace regresyon da kullanılan metotlar sonucu elde edilen denklemler gösterilmiştir. Bu denklemlerdeki $\alpha$ sayıları metotlar tarafından elde edilen parametrelerin sabit katsayılarıdır. Bu katsayılar Tablo 4 de verilmiştir. 
Tablo 4. Pace regresyon sonucu elde edilen denklemlere ait sabit katsaylları

\begin{tabular}{|c|l|l|}
\hline Sabit Katsayular & OLS Metot & Deneysel Bayes Metot \\
\hline$\alpha_{1}$ & -5.4629 & -5.2886 \\
\hline$\alpha_{2}$ & -70.3752 & -87.7759 \\
\hline$\alpha_{3}$ & 12.3236 & 11.0505 \\
\hline$\alpha_{4}$ & 0.036 & 0.0344 \\
\hline$\alpha_{5}$ & -27.5807 & -15.8959 \\
\hline$\alpha_{6}$ & 50.8164 & 50.7756 \\
\hline$\alpha_{7}$ & -0.0033 & -0.0019 \\
\hline$\alpha_{8}$ & 36070749.26 & 35658388.8 \\
\hline$\alpha_{9}$ & -424347.0142 & -289187.2354 \\
\hline$\alpha_{10}$ & 0.0001 & 0.0001 \\
\hline$\alpha_{11}$ & 517434.4623 \\
\hline$\alpha_{12}$ & 427551.6537 & -527670.6101 \\
\hline
\end{tabular}

Eşitlik (3) ve (4) e göre OLS (Model-1) ve Deneysel Bayes (Model-2) metodu tarafından tahmin edilen Q/A değerleri Şekil 3'te gösterilmiştir. Genel olarak Şekil 4 incelendiğinde, model sonuçları ile deneysel sonuçların benzer olduğu görülebilir.

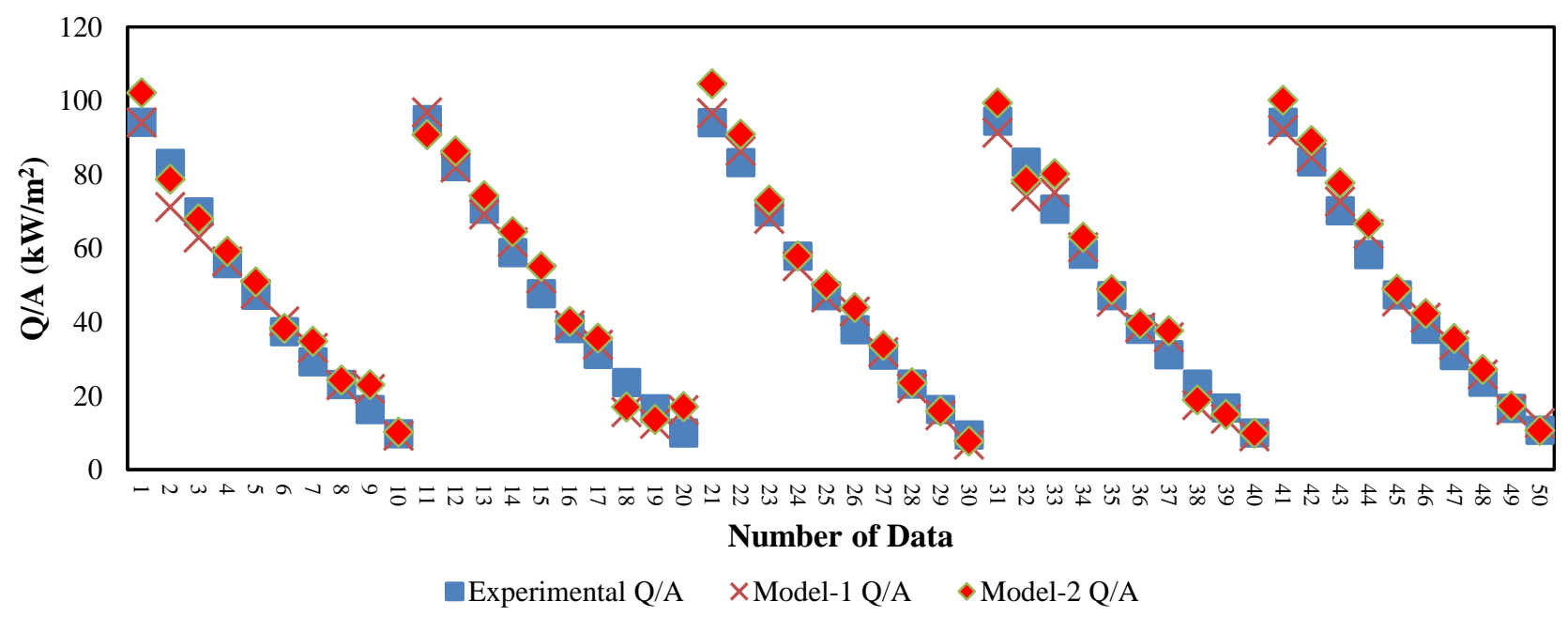

Şekil 4. Pace regresyon metotları ile tahmin edilen $Q / A$ değerleri

Pace regresyon analizi sonucu elde edilen modellerin hata analizleri Tablo 5 de verilmiştir. Tablo 5 e göre en az hata analizi Model1 de 0.132 RAE değeridir.

Tablo 5. Hata analiz sonuçları

\begin{tabular}{|l|l|l|}
\hline Hata Analizi & Model $\mathbf{- 1}$ & Model-2 \\
\hline RAE & 0.132 & 0.133 \\
\hline MAE & 3.1174 & 3.13 \\
\hline RMSE & 4.06 & 4.13 \\
\hline
\end{tabular}

\section{Sonuç}

Bu çalışmada çekirdekli kaynamada kaynama ısı transferini tahmini Pace regresyon analizi yöntemi ile gerçekleştirilmiştir. Pace regresyonda OLS ve Deneysel Bayes metotları kullanılmıştır. Bu metotlar sayesinde 1sı akısı (Q/A) değerleri için amprik eşitlikler elde edilmiştir. Bu eşitlikler yardımı ile çelik yüzeyde meydana gelen kaynama isı transferi değerleri elde edilmiştir. Elde edilen veriler deneysel veriler ile karşılaştırılmıştır. Verilen şartlar altında en iyi tahminin OLS metodu tarafından 0.132 RAE hata değeri ile gerçekleştirilmiştir. Bu durum Pace regresyon OLS' nın kaynama 1sı transferi tahmini için başarılı bir şekilde kullanılabileceğini göstermektedir. Kaynama ısı transferi çalışmalarında farklı metal yüzeyler kullanılarak daha fazla veri elde edilebilir ve böylece Pace regresyon analizinde daha az hatalı modeller elde edilebilir. 


\section{References (Kaynakça)}

[1] G. Su et al., "Applications of artificial neural network for the prediction of flow boiling curves," Journal of Nuclear Science and Technology, vol. 39, no. 11, pp. 1190-1198, 2002.

[2] S. A. Rushdi, "Prediction of Heat Transfer Coefficient of Pool Boiling Using Back propagation Neural Network Prediction of Heat Transfer Coefficient of Pool Boiling Using Back propagation Neural Network 」 Engineering and Technology Journal, $30(8), 2016$.

[3] M. Liang, X. Zhang, R. Zhao, X. Wen, and S. Qing, "Optimization of R245fa Flow Boiling Heat Transfer Prediction inside Horizontal Smooth Tubes Based on the GRNN Neural Network," vol. 2018, 2018.

[4] H. Badem, A. Basturk, A. Caliskan, and M. E. Yuksel, "A new efficient training strategy for deep neural networks by hybridization of artificial bee colony and limited-memory BFGS optimization algorithms," Neurocomputing, vol. 266, pp. 506-526, 2017.

[5] A. B. Demirpolat and M. Das, "Prediction of viscosity values of nanofluids at different $\mathrm{pH}$ values by alternating decision tree and multilayer perceptron methods," Applied Sciences (Switzerland), vol. 9, no. 7, 2019.

[6] H. M. Ertunc, "Prediction of the pool boiling critical heat flux using artificial neural network," IEEE Transactions on Components and Packaging Technologies, vol. 29, no. 4, pp. 770-777, 2006.

[7] S. A. Alavi Fazel, "A genetic algorithm-based optimization model for pool boiling heat transfer on horizontal rod heaters at isolated bubble regime," Heat and Mass Transfer/Waerme- und Stoffuebertragung, vol. 53, no. 9, pp. 2731-2744, 2017.

[8] E. Alic, O. Cermik, N. Tokgoz, and O. Kaska, "Optimization of the Pool Boiling Heat Transfer in the Region of the Isolated Bubbles using the ABC Algorithm," vol. 12, no. 4, pp. 1241-1248, 2019.

[9] E. Alic, M. Das, and O. Kaska, "Heat flux estimation at pool boiling processes with computational intelligence methods," Processes, vol. 7, no. 5, 2019.

[10]J. M. Barroso-Maldonado, J. A. Montañez-Barrera, J. M. Belman-Flores, and S. M. Aceves, "ANN-based correlation for frictional pressure drop of non-azeotropic mixtures during cryogenic forced boiling," Applied Thermal Engineering, vol. 149, no. November 2018, pp. 492-501, 2019.

[11]N. Parveen, S. Zaidi, and M. Danish, "Comparative analysis for the prediction of boiling heat transfer coefficient of R134a in micro/mini channels using artificial intelligence (AI)-based techniques," International Journal of Modelling and Simulation, vol. 40, no. 2, pp. 114-129, 2020.

[12] Peng, Y., Li, W., Luo, X., Li, H. A geographically and temporally weighted regression model for spatial downscaling of MODIS land surface temperatures over urban heterogeneous regions. IEEE Transactions on Geoscience and Remote Sensing, 57(7), 50125027, 2019.

[13] Wang Y, Witten IH. Modeling for optimal probability prediction. In: Proceedings of the 19th International Conference in Machine Learning, Sydney, Australia, 2002, pp. 650-7.

[14] Meshkin, A., Sadeghi, M., Ghasem-Aghaee, N. Prediction of relative solvent accessibility using pace regression. EXCLI J, 8, 211-217, 2009

[15] Wang JY, Ahmad S, Gromiha MM, Sarai A. Look-up tables for protein solvent accessibility prediction and nearest neighbor effect analysis. Biopolymers; 75:209-16, 2004.

[16] Das, M., Akpinar, E. K. Investigation of pear drying performance by different methods and regression of convective heat transfer coefficient with support vector machine. Applied Sciences, 8(2), 215, 2018.

[17]FAZEL, SA Alavi; JAMIALAHMADI, M. Semi-empirical modeling of pool boiling heat transfer in binary mixtures. International journal of heat and fluid flow, 44: 468-477, 2013. 